Piran, F. A. S., Neves, C. T., Sordi, J. D. \& Nunes, F. L. (2018). A economia compartilhada e a percepção de seus efeitos por parte dos estudantes de uma instituição de ensino superior. Consumer Behavior Review, 2(Special Edition), 69-80.

ISSN: 2526-7884

Editor: Prof. Dr. Marconi Freitas da Costa

Email da revista: cbr@ufpe.br
Avaliação: Double blind review

Recebido: 12 de Abril de 2018

Aceito: 27 de Julho de 2018

\title{
A economia compartilhada e a percepção de seus efeitos por parte dos estudantes de uma instituição de ensino superior
}

\author{
Fabio Antonio Sartori Piran \\ Camila Timm Neves \\ Jefferson Dobner Sordi \\ Fabiano de Lima Nunes
}

\section{Fabio Antonio Sartori Piran é Professor do Instituto do Ciências Sociais Aplicadas e Ciências Exatas e Tecnologia da Universidade Feevale. E-mail: fabiopiran@feevale.br. Camila Timm Neves é Especialista pela Universidade Feevale. \\ E-mail: camilatneves@hotmail.com. Jefferson Dobner Sordi é Professor do Instituto do Ciências Sociais Aplicadas da Universidade Feevale. E-mail: jefferson@feevale.br. Fabiano de Lima Nunes é Professor do Instituto do Ciências Sociais Aplicadas e Ciências Exatas e Tecnologia da Universidade Feevale. E-mail: fabianonunes@feevale.br. Os autores agradecem aos avaliadores pelos comentários para melhoria do artigo.}

\begin{abstract}
Resumo
Em momentos de instabilidade financeira, surgem dúvidas relacionadas ao mercado financeiro e à situação econômica de um país. Esses momentos são propícios para o surgimento de novos movimentos econômicos, como, por exemplo, a economia compartilhada. Entende-se como relevante desenvolver trabalhos que analisem a percepção da sociedade sobre os efeitos proporcionados pela economia compartilhada. Buscando contribuir neste sentido, o objetivo deste trabalho é analisar a percepção de uma parcela dos cidadãos quanto aos efeitos econômicos e sociais proporcionados pela economia compartilhada no seu padrão atual de vida. Para cumprir o objetivo proposto, foi realizada uma survey com alunos de uma Instituição de Ensino Superior no Rio Grande do Sul - Brasil. Dentre os principais resultados, percebeu-se que uma faixa de $67,9 \%$ a $83,3 \%$ dos respondentes concorda totalmente com a afirmativa de que a economia compartilhada gera impactos sociais e econômicos positivos, o que possibilita mudança no seu padrão atual de vida. Identifica-se que a economia compartilhada surge de uma dicotomia entre a oportunidade de gerar novos negócios e uma resposta a crises econômicas. Além disso, proporciona facilidade no momento de efetuar compras, conexão e contato entre pessoas conhecidas e desconhecidas, compartilhamento de informações através de sites de pesquisa e aplicativos de busca, além da possibilidade de fazer negócios e economizar dinheiro.

Palavras-chave: Economia Compartilhada, Modelo de Negócios, Consumo Colaborativo, Geração do Milênio.
\end{abstract}




\section{INTRODUÇÃO}

Um dos maiores desafios contemporâneos para acadêmicos, gestores e a sociedade é a utilização eficiente dos recursos (Leismann et al., 2013). Os padrões e níveis atuais de consumo nas economias industriais são reconhecidos como insustentáveis. Assim, o excesso de consumo e a cultura do desperdício são responsáveis por problemas ambientais, tais como esgotamento de recursos e geração excessiva de resíduos (Piscicelli et al., 2015).

Neste contexto, surge a economia compartilhada como uma possível solução para evitar o uso desnecessário de recursos e o desperdício excessivo, promovendo a redução de novas compras, o uso de ativos ociosos e a reutilização de produtos (Bostman \& Rogers, 2011; Piscicelli et al., 2015). A partir desse cenário, a economia compartilhada apresenta um novo formato em que a partilha promove um movimento de transformação perturbador aos tradicionais modelos de negócios. Empresas como a eBay, Airbnb, TaskRabbit, BlaBlaCar, Uber, Zipcar, Flickr, Freecycle, foram criadas baseados nesse movimento (Belk, 2014; Piscicelli et al., 2015).

A economia compartilhada trata-se de um emergente modelo socioeconômico baseado na partilha, aluguel, escambo, troca e financiamentos colaborativos. A partir desse modelo, o consumo colaborativo potencializa-se pela interação entre comunidades e, principalmente, pelo uso das tecnologias de rede. Esse tema está ampliando seu espaço na economia, pois constantemente surgem novas formas de compartilhamento, enfatizando que não é necessário possuir um bem, mas sim ter acesso aos benefícios propostos (Denning, 2014; Rifkin, 2014).

Esse movimento gera novos negócios a partir das mudanças sociais e culturais, em particular a possibilidade de as pessoas optarem pelo acesso ao bem ou ao serviço em detrimento à posse. A economia compartilhada provoca a sociedade no que tange ao consumo de massa (Rifkin, 2014). A partir da capacidade de abordar interesses econômicos alinhados com impactos sociais e ambientais positivos, a economia compartilhada tem recebido atenção nos últimos anos como um modelo promissor para o consumo sustentável. Mesmo com casos de sucesso e um vasto potencial de negócios inexplorado, a pesquisa acadêmica ainda é escassa no tocante ao tema da economia compartilhada (Tukker \& Tischner, 2006; Piscicelli et al., 2015). Assim, apresenta-se um cenário de oportunidades para pesquisas, em prol do entendimento dos impactos proporcionados pela economia compartilhada na sociedade.

A partir desse contexto, esta pesquisa visa analisar a percepção de uma parcela dos cidadãos quanto aos efeitos econômicos e sociais proporcionados pela economia compartilhada no seu padrão atual de vida. Além desta introdução, o trabalho apresenta uma revisão teórica sobre economia compartilhada e consumo colaborativo. $\mathrm{Na}$ sequência os procedimentos metodológicos são delineados e a análise de resultados e conclusões são apresentadas.

\section{REVISÃO TEÓRICA}

Percebe-se uma mudança da era do capitalismo para a era da colaboração (Ritzer \& Jurgenson, 2010; Ritzer, Dean \& Jurgenson, 2012). Colaborar e compartilhar são fenômenos tão antigos quanto a humanidade, enquanto o consumo colaborativo e a economia compartilhada são fenômenos oriundos da era da Internet. A Internet trouxe novas formas de partilha, bem como a promoção de formas mais antigas de compartilhamento em uma escala maior, como, por exemplo, a transferência ou uso dos bens materiais entre consumidores (Belk, 2014). Em vez de possuir coisas, os consumidores querem acesso a bens e preferem pagar pela experiência de acessá-los temporariamente (Bardhi \& Eckhardt, 2012).

A compreensão da sociedade sobre "o acesso aos bens comuns" tem avançado pela indústria de transformação e de serviços. Dois dos principais afetados, por exemplo, são a indústria de transportes e o mercado de hospedagens. Isso porque negócios de compartilhamento como Uber (transporte) e AirBnB (hospedagem) têm maior probabilidade de aceitação pelo consumidor, pois propõem o compartilhamento de ativos de alto valor agregado (El Fassi et al., 2012). Um aspecto central que auxilia nessa compreensão é a observação de que a percepção do veículo como símbolo de status está diminuindo no mundo (Shaheen et al., 2012).

A economia compartilhada é um sistema socioeconômico construído em torno do compartilhamento dos recursos físicos e humanos e inclui a produção, criação, distribuição, comércio e consumo compartilhado de bens e serviços por organizações e pessoas (Gansky, 2010). Já o consumo colaborativo pode ser entendido como um conjunto de práticas comerciais que possibilitam o acesso aos bens e serviços em detrimento da posse (Bostman \& Rogers, 2011). 
Importante destacar que Martin (2016) utiliza os dois termos - economia compartilhada e consumo colaborativo - de forma intercambiável, explicando o mesmo fenômeno, e que o presente artigo também segue por esse mesmo caminho.

Uma das possibilidades das práticas compartilhadas é a conexão de consumidores e pessoas com interesses comuns. Essas conexões, chamadas de peer-to-peer (pessoa a pessoa), eliminam intermediários e possibilitam a economia de recursos físicos e financeiros (Dubois, Schor \&
Carfagna, 2014). Os fatores tecnológicos proporcionaram a disseminação das redes sociais e a redução dos custos das transações peer-to-peer, provendo o contato direto entre consumidor $\mathrm{e}$ fornecedor, reduzindo o custo nas intermediações (Bostman \& Rogers, 2011). Ainda para Bostman e Rogers (2011) a economia compartilhada possui quatro princípios essenciais, que possibilitam o seu funcionamento. Os quatro princípios colaborativos são apresentados no Quadro 1.

\begin{tabular}{|c|c|}
\hline Princípio & Descrição \\
\hline Massa crítica & $\begin{array}{l}\text { Considera dois pontos fundamentais. O primeiro refere-se à escolha. Isso porque é } \\
\text { necessário que exista variedade e quantidade nas escolhas, para que seja possível competir } \\
\text { com o modelo de consumo tradicional. O segundo refere-se à capacidade de formação de } \\
\text { clientes fiéis ao movimento. Para Porter (2009), a massa critica é a quantidade de usuários } \\
\text { necessária para sustentar a prática económica. }\end{array}$ \\
\hline Capacidade ociosa & Considera a capacidade de aproveitar a capacidade ociosa e busca redistribui-la. \\
\hline $\begin{array}{l}\text { Crença no bem } \\
\text { comum }\end{array}$ & Termo aplicado a recursos que pertencem a todos os cidadãos. \\
\hline $\begin{array}{l}\text { Confiança entre } \\
\text { desconhecidos }\end{array}$ & $\begin{array}{l}\text { Exige confiar em alguém desconhecido em diferentes graus, dependendo do tipo de negócio } \\
\text { efetuado. }\end{array}$ \\
\hline
\end{tabular}

Fonte: Adaptado de Bostman e Rogers (2011)

Quadro 1: Princípios da economia compartilhada

Os princípios básicos da economia compartilhada são vitais para que ocorra o processo de compartilhamento entre indivíduos no mundo digital. Assim, a confiança entre desconhecidos se dá por intermédio de sua reputação (Schor, 2014). A reputação do indivíduo determina a confiabilidade com base no comportamento on-line do participante. Os consumidores depositam confiança através dos comentários gerados pelo consumidor on-line, quanto à recomendação de produtos e serviços (Rifkin, 2014).

A economia compartilhada se resume em mudar a lógica da propriedade privada para o acesso compartilhado. A economia compartilhada também propõe mudar nosso modelo de vida e consumo. Nesse sentido, a proposta é desperdiçar menos o tempo e dinheiro com "coisas". Assim, as pessoas experimentam esses serviços porque são mais baratos que os tradicionais, e aderem ao movimento devido à variedade de escolhas disponíveis e à necessidade de se conectar com pessoas (Gansky, 2010). Desta forma quanto maior o número de pessoas que aderirem ao movimento (massa crítica), mas facilmente a prática econômica é sustentada e desenvolvida (Porter, 2009).

Apesar de esses exemplos variarem nos termos de escala, maturidade e finalidade, as atividades econômicas da economia compartilhada propõem a existência de três sistemas (Bostman \& Rogers, 2011), conforme apresentado no Quadro 2.
Sistemas

Sistema de produtos e serviços

Mercado de

distribuição

\section{Descrição}

"Mentalidade de uso", ou seja, ter acesso ao bem sem ter que adquiri-lo. As pessoas efetuam o compartilhamento através da utilização da propriedade privada de empresas ou terceiros É a reutilização ou revenda de produtos, através de redes sociais e aplicativos que possibilitam a conexão entre desconhecidos. Conforme Bostman e Rogers (2011), o mercado de redistribuição é visto como quinto "R": reduzir, reciclar, reutilizar, reformar e redistribuir

Estilos de vida $\quad$ Trata-se da aderência de pessoas com interesses comuns, com o objetivo de compartilhar colaborativos $\quad$ ativos menos tangíveis.

Fonte: Adaptado de Bostman e Rogers (2011).

Quadro 2: Sistemas da economia compartilhada 

superior

Recentemente, no Brasil e no mundo, é possível encontrar várias empresas que aderiram ao movimento colaborativo (Villanova, 2015). O Quadro 3 apresenta algumas dessas atividades econômicas compartilhadas, a partir dos sistemas desenvolvidos por Bostman e Rogers (2011), segregados por tipos de negócios.

\begin{tabular}{|l|l|}
\hline \multicolumn{2}{|c|}{ Sistemas } \\
\hline \multirow{5}{*}{ Sistemas de serviço de produtos } & Bike Rio (compartilhamento de bicicletas) \\
& B-cycle - EUA (compartilhamento de bicicletas) \\
& Zascar (car sharing- B2P) \\
Zipcar - EUA, Street Car - UK (car sharing- B2P) & RelayRides - EUA (car sharing- P2P) \\
& Netflix (compartilhamento de filmes) \\
& Buscalá (aluguel de produtos diversos) \\
\hline \multirow{5}{*}{ Mercado de distribuição } & TemAçucar (empréstimos e doação entre vizinhos) \\
& Tomaladaca (troca de produtos e serviços) \\
& Xcambo (troca de produtos) \\
& Trocandolivros (troca de livros) \\
& Projeto Gaveta (clothing swap - troca de roupas) \\
& Trocacasa (troca de casas entre viajantes pelo mundo) \\
\hline \multirow{5}{*}{ Estilo de vida colaborativo } & The HUB (coworking) \\
& Nós (coworking) \\
& Couchsurfing (compartilhamento de hospedagem - gratuito) \\
& Airbnb (compartilhamento de hospedagem) \\
& Zimride - EUA (sistema de caronas) \\
& Wegocaronas, ponga.mobi, Tripda (sistema de caronas) \\
& KickStarter - EUA (crowdfunding) \\
& Catarse (crowdfunding) \\
& Wikipedia (crowdsourcing) \\
& Bliive (troca de serviço - banco de tempo) \\
& Timerepublik (troca de serviço - banco de tempo) \\
\hline &
\end{tabular}

Fonte: Villanova (2015).

Quadro 3: Atividades da economia compartilhada

Freitas et al. (2016) identificam dez características dos modelos de negócio de consumo colaborativo. Quatro dessas características foram consideradas como as principais: tipo de plataforma, transação financeira envolvida, modelo e tipo de compartilhamento. Elas surgiram da análise de 72 sites de economia compartilhada. A partir disso, dois tipos de consumo colaborativo foram estabelecidos: novas oportunidades econômicas e consumo de intenção ideológica. A Figura 1 apresenta os diferentes motivadores para adoção do consumo colaborativo, a partir do seu tipo.

Ainda sobre a adoção da economia compartilha, Silveira et al., (2016) identificaram que 48\% da literatura referente ao tema busca compreender quais os direcionadores do consumo colaborativo. Existem três grandes elementos de empoderamento e três de resistência à economia compartilhada. Sob o ponto de vista de reforçar essa nova tendência, o consumo colaborativo é entendido como (a) uma oportunidade econômica, capaz de promover (b) um consumo sustentável, diminuindo o nível de ociosidade que resultaria em (c) uma descentralização da economia, promovendo uma maior justiça para o ambiente social (Martin, 2016).

Do lado das resistências, Martin (2016) critica a economia compartilhada como sendo um caminho para (a) mercados desregulados, sem o recolhimento de impostos e com altos riscos aos consumidores, além de (b) reforçar o neoliberalismo com as relações de trabalho casuais através de (c) inovações incoerentes, uma vez que as terminologias tendem a ser confusas e com impactos variados. A questão reflexiva do trabalho de Martin (2016) é apresentar uma dicotomia para o consumo colaborativo: ou é uma forma de caminho à sustentabilidade ou uma reinvenção do neoliberalismo. 


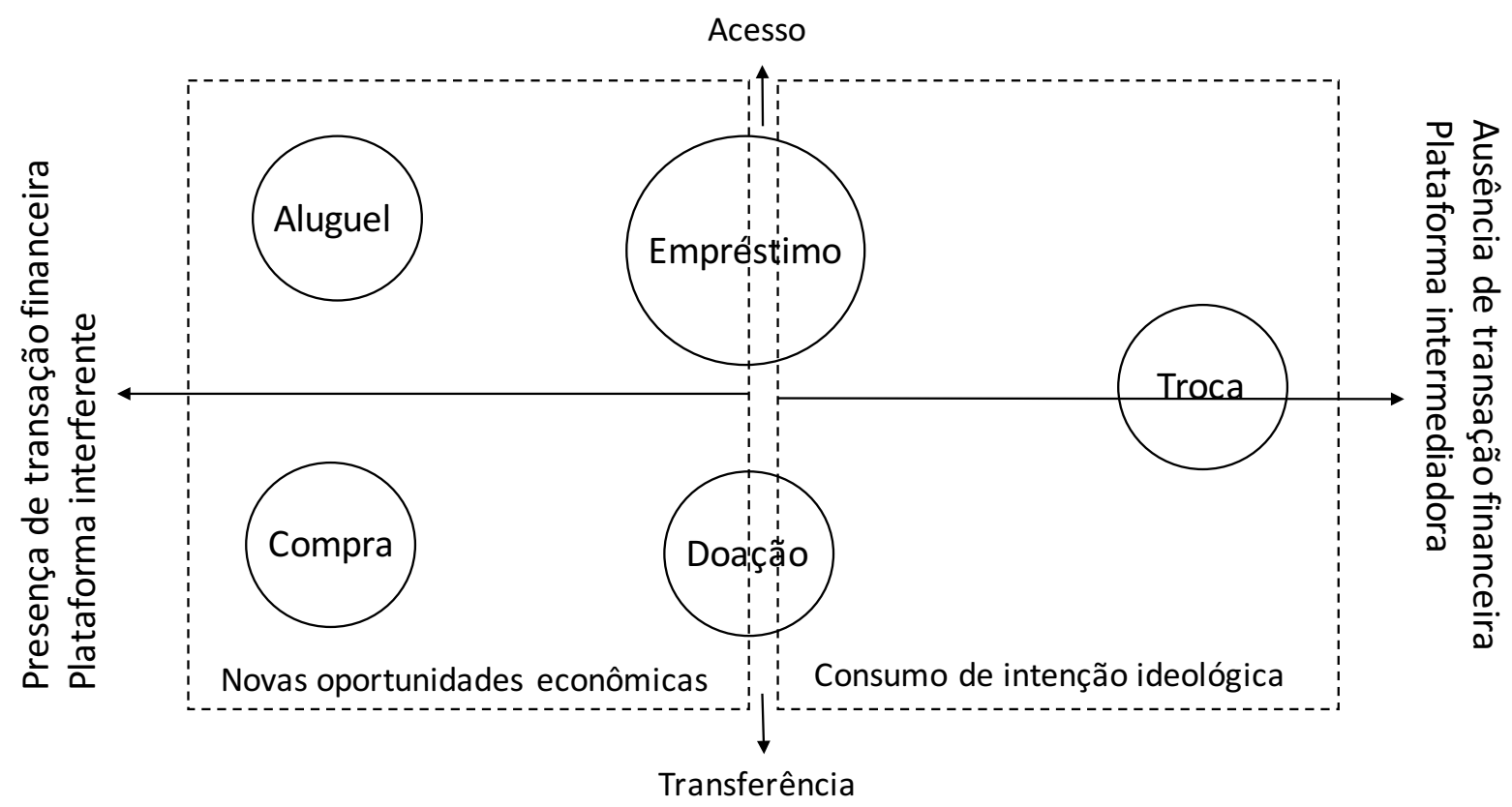

Fonte: Freitas et al. (2016).

Figura 1: Tipos de consumo colaborativo

Após a apresentação dos conceitos em relação ao tema estudado, a próxima seção descreve os aspectos metodológicos utilizados na condução da pesquisa.

\section{METODOLOGIA}

Foi adotada uma pesquisa aplicada, pois proporciona conhecimentos para a aplicação dos conceitos teóricos na pratica. Quantos aos seus fins e objetivos, a pesquisa pode ser considerada como descritiva, o que se deve ao fato de os pesquisadores descreverem e analisarem os dados, porém sem efetuar qualquer tipo de interferência, para alcançar os objetivos pesquisados. A pesquisa descritiva é caracterizada por ter como objetivo primordial a descrição das particularidades de determinada população, fenômeno ou estabelecimento de relação entre variáveis. Por fim, o trabalho utiliza-se da pesquisa quantitativa, sendo que foi aplicado um questionário, em uma determinada amostra de pessoas, composta por alunos de uma Instituição de Ensino Superior (Prodanov \& Freitas, 2009).

\section{Método de coleta}

$\mathrm{Na}$ etapa inicial do estudo, foi efetuada uma revisão da literatura, com a finalidade de definir o objetivo do estudo e o modelo de pesquisa.
Posteriormente foi definida a aplicação de uma survey como método de trabalho. Assim, devido ao acesso aos respondentes, uma amostra por conveniência foi selecionada e evidências foram coletadas durante a etapa de coleta de dados. $\mathrm{Na}$ última etapa, efetuou-se a análise de dados, de acordo com as respostas obtidas. Essas análises proporcionaram a identificação e descrição dos resultados.

Para a coleta de dados, o questionário foi elaborado através da revisão da literatura, contendo questões que buscam identificar a relação entre a economia compartilhada e os seus efeitos na vida da sociedade. Assim, os aspectos investigados e os autores que serviram como base para a elaboração das perguntas são apresentados no Quadro 4.

Utilizou-se uma ferramenta online, o Google Forms, para elaboração e envio do questionário, o qual é composto de doze perguntas, organizadas da seguinte forma: as questões de 1 a 4 são focadas em traçar o perfil demográfico dos entrevistados, enquanto as demais questões estão relacionadas ao grau de conhecimento e à representação quanto aos impactos da economia compartilhada na vida da sociedade. Para Hsieh e Dawson (2010), o Google Forms é uma alternativa rápida e de baixo custo para a criação de perguntas online e para analisar os seus resultados (Hsieh \& Dawson, 2010; Spaeth \& Black, 2012; Nunes, 2016). 


\begin{tabular}{|l|l|}
\hline \multicolumn{2}{|c|}{ Aspectos investigados } \\
\hline Perfil do entrevistado & Prodanov e Freitas (2009) \\
\hline \multirow{3}{*}{ Compartilhamento } & Gansky (2010) \\
Peer-to-Peer & Bostman e Rogers (2011) \\
& Schor (2014) \\
& Rifkin (2014) \\
& Belk (2014) \\
\hline \multirow{3}{*}{ Modelos de negócios } & Gansky (2010) \\
& Bostman e Rogers (2011) \\
& Schor (2014) \\
& Rifkin (2014) \\
& Belk (2014) \\
\hline \multirow{2}{*}{$\begin{array}{l}\text { Três sistemas da economia } \\
\text { compartilhada }\end{array}$} & Gansky (2010) \\
& Bostman e Rogers (2011) \\
& Schor (2014) \\
& Rifkin (2014) \\
\hline
\end{tabular}

Fonte: Elaborado pelos autores.

Quadro 4: Principais aspectos investigados da economia compartilhada

O questionário foi encaminhado para 400 entrevistados da IES pesquisada. Foram obtidas 247 respostas, correspondentes a uma taxa de retorno de respostas de $61,75 \%$. A taxa de retorno foi satisfatória, observando-se parâmetros detectados na literatura (entre $31 \%$ e $46 \%$ ) (Sheehan, 2001). Foi solicitado aos entrevistados que indicassem uma pontuação para as respostas de cada questão, utilizando uma escala Likert de 1 a 5 (Fan \& Yan, 2010; Menezes et al., 2016). Na fase de análise, incialmente os dados obtidos foram tabulados em planilhas eletrônicas (MS Excel). Na sequência, utilizou-se estatística descritiva para a apresentação gráfica dos resultados. Posteriormente os dados foram comparados com a abordagem teórica da pesquisa, para a viabilidade da análise e discussão dos resultados.

\section{ANÁLISE DE DADOS}

A análise de dados está dividida em três seções. $\mathrm{Na}$ primeira, é identificado o perfil do aluno que respondeu à survey, seguida pela análise do seu grau de conhecimento e relevância sobre o assunto e, por último, é analisada a sua percepção quanto à utilização da economia compartilhada.

\section{Características demográficas da amostra}

A Tabela 1 apresenta os cursos de formação nos quais os alunos estão matriculados e o percentual que representam dentro da amostra.
Tabela 1

Taxa de Retorno por curso

\begin{tabular}{lcc}
\multicolumn{1}{c}{ Curso } & Responderam & Percentual \\
\hline Ciência Computação & 18 & $7,29 \%$ \\
Engenharia & 32 & $12,96 \%$ \\
Mecânica & & \\
Engenharia de & 51 & $20,65 \%$ \\
Produção & & \\
Engenharia Química & 41 & $16,60 \%$ \\
Engenharia Civil & 34 & $13,77 \%$ \\
Gestão Ambiental & 12 & $4,86 \%$ \\
Administração de & 49 & $19,84 \%$ \\
empresas & & \\
Engenharia & 10 & $4,05 \%$ \\
Eletrônica & & \\
\hline Fonte: Elaborado &
\end{tabular}

Fonte: Elaborado pelos autores.

Dentre os principais percentuais, foi possível identificar que $87,85 \%$ da amostra são da área de engenharia, e que $20,65 \%$ dos alunos estão matriculados no curso de engenharia de produção.

Quanto ao público que participou do estudo, identificou-se que a maioria dos respondentes (57,50\% da amostra) é do gênero masculino. Já a faixa etária está dividida entre as seguintes faixas: 17 a 24 anos, com 110 respondentes; 25 a 29 anos, com 81 respondentes; 30 a 34 anos, com 35 respondentes; 35 a 40 anos, com 13 respondentes; 41 a 45 anos, com 2 respondentes; e acima de 45 anos, com 6 respondentes. Percebe-se que a maior parte dos respondentes está na faixa de 17 a 34 anos $(91,50 \%)$. Essa é a geração do milênio (millennum generation), que está promovendo o movimento da economia compartilhada (Cheng, 2016). 
Quanto à renda dos alunos que responderam ao questionário, identificou-se que $47,77 \%$ da amostra recebe até $\mathrm{R} \$ 1.760,00$ reais, $34,01 \%$ está na faixa salarial entre $R \$ 1.761,00$ e $R \$ 3.520,00$, enquanto que $18,22 \%$ da amostra tem renda de $\mathrm{R} \$ 3.521,00$ ou mais. Após as análises demográficas, nos próximos itens será abordada a análise dos dados referentes ao seu conhecimento de assunto, utilização do serviço e percepção sobre a influência da economia compartilhada no seu modelo de vida.

\section{Relevância sobre o assunto}

Foi solicitado aos respondentes que indicassem um valor para as respostas de cada questão, utilizando uma escala Likert de 1 a 5 (1- Nenhum, 2 - Pouco, 3 - Razoável, 4 - Bom e 5 - Muito bom). Parte das perguntas referia-se ao grau de conhecimento do respondente sobre o assunto. Foi possível a obtenção dos seguintes resultados: $66,80 \%$ dos respondentes acredita que tem um bom ou razoável grau de conhecimento e interesse sobre o assunto abordado (economia compartilhada), sendo que $68,83 \%$ da amostra identifica que conhece e já utilizou algum serviço ou produto compartilhado.

Quanto ao grau de interesse em obter informação sobre a economia compartilha, 91,90\% dos respondentes informam positivamente. Quanto à relevância do assunto numa abordagem acadêmica, por exemplo, 93,12\% dos respondentes destacaram que se trata de um tema relevante para ser estudado e compreendido.

Questionou-se os respondentes sobre a visão pessoal do movimento de compartilhamento, com o objetivo de compreender se, no seu entendimento, a economia compartilhada pode ser entendida como uma nova tendência econômica ou seria um simples modismo. Nesse sentido, 97\% dos respondentes compreendem que se trata de uma nova tendência econômica, e que a economia compartilhada não é apenas um modismo para auxiliar num momento de crise financeira. Tal resultado vai ao encontro da descoberta de Martin (2016) sobre um dos pontos de empoderamento da economia compartilhada. Ao enquadrar o consumo colaborativo como uma oportunidade econômica o autor comenta que esse movimento estimula as pessoas a ganharem seu próprio dinheiro, fazendoas microempreendedoras.

Dentre os três sistemas existentes na economia compartilhada (sistema de produtos e serviços, mercado de redistribuição e estilo de vida colaborativo), buscou-se compreender qual tem maior potencial de utilização no Brasil, segundo a amostra pesquisada. A Figura 2 mostra que $42 \%$ da amostra que respondeu ao questionário, optou pelo mercado de redistribuição, $38 \%$ optou pelo estilo de vida colaborativo, e $20 \%$, pelo sistema de produto e serviço.

Dessa forma, a maioria dos respondentes entende que através da economia compartilhada existe uma oportunidade de revender algo que não utiliza mais, e entende o mercado como uma possibilidade de ganhar dinheiro. Esta análise pode estar ligada ao perfil do respondente, tendo em vista que o maior percentual da amostra está na faixa etária entre 17 e 24 anos e tem renda de até R\$ $1.760,00$ reais. Segundo Rifkin (2014), os jovens reconhecem que não precisam ter coisas para usufruir delas e que, quando agem em conjunto, podem ter acesso a produtos e serviços.

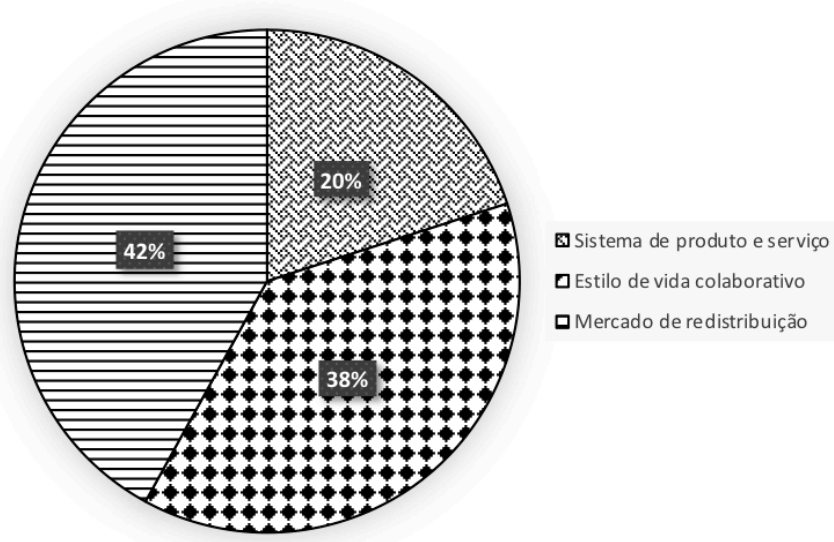

Fonte: Elaborado pelos autores

Figura 2: Potencial de negócios da economia compartilhada no Brasil 
Considerando que a literatura (Bostman \& Rogers, 2011; Piscicelli et al., 2015) aponta o sistema de produto e serviço é uma das estratégias que mais crescem no movimento da economia compartilhada, questionou-se aos respondentes qual a sua percepção especificamente sobre o potencial de crescimento deste sistema (sistema de produto e serviço). O resultado obtido contrasta com a literatura, pois, apenas $18 \%$ da amostra respondeu que acredita que o sistema de produtos e serviços tem possibilidade de crescimento, ou seja, a maior parte dos respondentes ainda não conseguiu identificar potencial de negócios em compartilhar seus bens ou prestar algum tipo de serviço, ou talvez, não está disposta a dividir. Belk (2014) relaciona esse tipo de resultado a questões comportamentais, como sentimentos de posse e apego associados ao status, gerando um empecilho para a participação da pessoa na economia compartilhada.

No entanto, o modelo de negócios do sistema de produtos e serviços é o mercado que mais que cresceu dentro da economia compartilhada (Rifkin, 2014). Empresas como Uber e Airbnb representam este crescimento. Cusumano (2015) refere-se a esses modelos como exemplo de sustentabilidade com propostas que agregam valores, as quais são perceptíveis ao consumidor.

Considerando os três tipos de sistema da economia compartilhada, e compreendendo como cada um dos modelos funciona e se aplica na sociedade, questionou-se aos respondentes o que os levaria e o que não os levaria a participar do movimento compartilhado.

Quanto ao fato de utilizar o serviço, $95,3 \%$ da amostra respondeu que buscaria com a economia compartilhada uma forma de economizar e de ganhar dinheiro, e $72,1 \%$ observa a possibilidade de fazer o bem ao meio ambiente. Bostman e Rogers (2011) afirmam que através da economia compartilhada as pessoas têm o acesso a uma maior quantidade de mercadorias, sem que haja a necessidade de produção, reduzindo o impacto global.

Esses dois resultados convergem às dimensões de custos e sustentabilidade da economia compartilhada (Lamberton \& Rose, 2012; Hamari, Sjöklint \& Ukkonen 2015; Mohlmann, 2015). Ressalva-se, ainda, nessa questão que apenas 36\% da amostra optaria por ter novas experiências, e $16 \%$ uma maior integração com a comunidade. Destaca-se como interessante esse resultado, pois nos dias atuais identifica-se que cada vez mais as pessoas estão conectadas a uma rede social, seja ela, Facebook, Twitter, WhatsApp, dentre outras (Gansky, 2010).

Analisando as respostas da amostra sobre o que não levaria o respondente a utilizar os serviços da economia compartilhada, $72,6 \%$ das respostas apontou para a falta de segurança e confiança, a qual pode estar voltada a aplicativos e pessoas. Para Schor (2014), com o aumento das interações virtuais, nas quais as partes não se conhecem, é necessário criar mecanismos que possam medir a reputação, agregando confiança e ganhando importância no relacionamento com os clientes. Como vimos anteriormente, a confiança é um dos princípios essenciais para o funcionamento da economia compartilhada (Bostman \& Rogers, 2011) e mais uma das dimensões da economia compartilhada (Lamberton \& Rose, 2012; Hamari et al., 2015; Mohlmann, 2015).

Outro ponto interessante de análise com relação aos pontos que os afastam do consumo colaborativo é que $37,7 \%$ dos alunos que responderam apontaram para a falta de estrutura no Brasil, e $42,6 \%$ para a falta de cultura de colaboração, aspectos ligados a nossa cultura e a nossa forma de interagir com os meios. Percebe-se então que existe uma lacuna entre a atitude e o comportamento (Belk, 2014; Hamari et. Al., 2015). Segundo Schor (2014), a economia compartilhada exige uma mudança de comportamento e dos padrões culturais de consumo.

\section{Percepção dos impactos da economia compartilhada}

Para avaliar a percepção dos respondentes quanto aos impactos da economia compartilhada, inicialmente solicitaram-se informações relativas à participação ou utilização de algum movimento colaborativo, com a utilização de uma escala Likert de 1 a 5 (1 - Não sei do que se trata; 2 - Nunca; 3 - Somente uma Vez; 4 - Sim, de vez em quando; 5 - Sim, com frequência). A Tabela 2 apresenta quais foram as respostas apresentadas pelos respondentes. Os números em cada linha identificam a quantidade de pessoas que respondeu sobre o assunto.

Percebe-se que uma parcela significativa dos respondentes indicou que nunca utilizou nenhum dos movimentos de compartilhamento citados. Poucos utilizam algum serviço colaborativo frequentemente. Essa análise mostra indícios contraditórios em relação às respostas anteriores, visto que os respondentes consideram a economia compartilhada importante, mas não a utilizam. 
Além disso, se os resultados da Tabela 2 forem confrontados com as respostas anteriores, pode-se sugerir que a amostra da pesquisa pode apresentar dúvidas quanto ao funcionamento e à utilização da economia compartilhada. Também se percebe que o movimento de colaboração tem muito a desenvolver, podendo oferecer muitas oportunidades de negócios, principalmente no Brasil.

\section{Tabela 2}

Uso do movimento colaborativo

\begin{tabular}{cccccc}
$\begin{array}{c}\text { Movimento } \\
\text { Colaborativo }\end{array}$ & $\begin{array}{c}\text { Sim, com } \\
\text { frequência }\end{array}$ & $\begin{array}{c}\text { Sim, de vez em } \\
\text { quando }\end{array}$ & $\begin{array}{c}\text { Somente uma } \\
\text { vez }\end{array}$ & $\begin{array}{c}\text { Nunca } \\
\text { Não sei do que } \\
\text { se trata }\end{array}$ \\
\hline Troca ou Aluguel de Livros & 22 & 99 & 48 & 77 & 1 \\
$\quad$ Bicicletas & 5 & 20 & 32 & 189 & 1 \\
$\begin{array}{c}\text { Associação a Empresas } \\
\text { Aluguel ou }\end{array}$ & 3 & 46 & 22 & 169 & 7 \\
$\begin{array}{c}\text { Compartilhamento de } \\
\text { Veículos }\end{array}$ & 4 & 47 & 34 & 161 & 1 \\
$\begin{array}{c}\text { Problemas Sociais } \\
\text { Serviços Coletivos }\end{array}$ & 13 & 55 & 50 & 126 & 3 \\
$\begin{array}{c}\text { Troca de Roupas } \\
\text { Compartilhamento de }\end{array}$ & 10 & 63 & 38 & 134 & 2 \\
$\quad$ Escritório & 33 & 83 & 34 & 97 & 0 \\
$\begin{array}{c}\text { Financiamento para } \\
\text { viabilização de projeto }\end{array}$ & 21 & 49 & 16 & 159 & 2 \\
Soluções para Empresas & 2 & 22 & 22 & 196 & 5 \\
Hospedagem & 4 & 19 & 28 & 193 & 3 \\
\hline
\end{tabular}

Fonte: Elaborado pelos autores.

Quanto à forma de consumo do movimento compartilhado versus a do mercado atual, foram solicitados aos respondentes identificar o que os levaria a aderir ao movimento. Em uma visão global 22,67\% (56) dos respondentes identificaram a economia compartilhada como uma nova possibilidade de negócios, sendo que 20,24\% (50) dos respondentes acreditam que a sua utilização possa estar relacionada ao momento de uma crise econômica, conforme apresenta a Figura 3. De fato, uma resposta pode estar ligada à outra, considerando-se que, com o mercado em recessão e com o aumento do desemprego, as pessoas iram encontrar novas alternativas de consumo (Gansky, 2010; Martin, 2016).

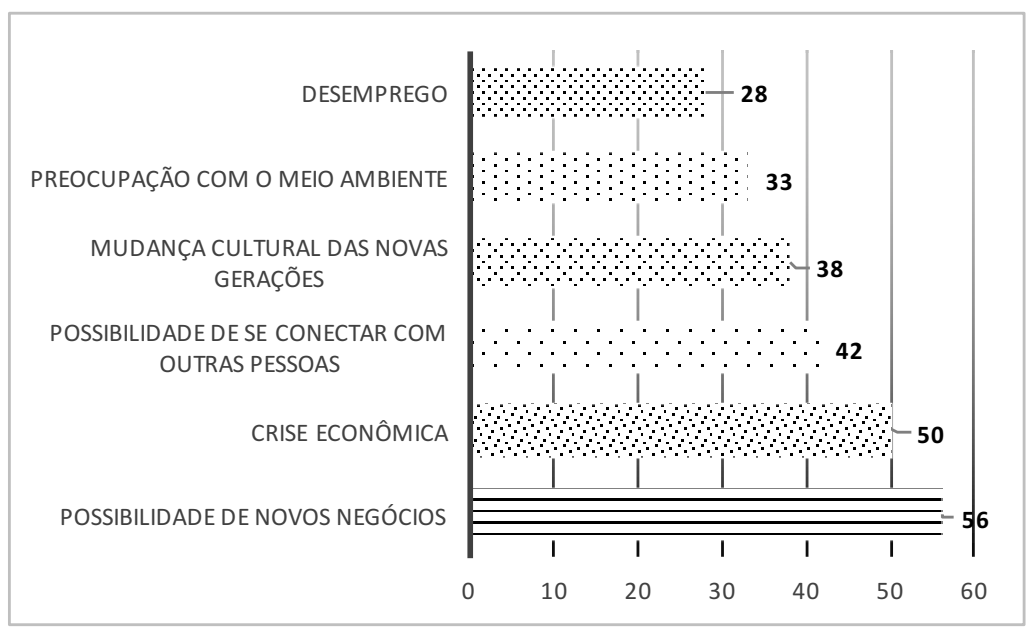

Fonte: Elaborado pelos autores.

Figura 3: Aderência ao movimento de compartilhamento 
Quanto a uma análise sob os aspectos ambiental e sustentável, $33 \%$ dos respondentes entendem o consumo compartilhado como uma nova forma de cuidar dos recursos naturais. Segundo Gansky (2010), a economia compartilhada apresenta uma postura mais ativa em relação às questões sociais, econômicas e sustentáveis, ao desenvolver modelos de negócios que busquem por essas gerações de valores. Com base nesses preceitos e fatores sociais, na economia compartilhada constata-se uma crescente preocupação com questões relacionadas ao meio ambiente e sustentabilidade (Dubois et al., 2014). A base da economia compartilhada é constituída por modelos de negócios criados através de plataformas on-line, algumas sustentáveis, parte das quais favorece a criação de novas relações econômicas, enquanto outras podem reproduzir os padrões atuais da economia (Schor, 2014).

As redes sociais, a conexão com outras pessoas, tem crescido a cada dia por intermédio da Internet. Nos dias atuais, se comunicar com uma pessoa distante tornou-se barato e acessível. Assim, 42\% dos respondentes aderem ao movimento motivados pelo desejo de fazer novas conexões (Schor, 2014). Por fim, 38\% respondentes indicaram que, para que a economia compartilhada seja impulsionada, é necessária uma mudança cultural das novas gerações.

Também se questionou aos respondentes qual a sua compreensão sobre como os avanços dos meios digitais, o contato com as redes sociais e a facilidade em fazer negócios e buscar conhecimento podem ter alterado o seu modelo de vida atual. Para essa questão, foi utilizado novamente o modelo de pergunta através da escala Likert de 1 a 5, sendo 1 - Discordo completamente, 2 - Discordo, 3 - Não concordo nem discordo, 4 - Concordo e 5 - Concordo plenamente.

Os resultados apresentam uma faixa de $67,9 \%$ a $83,3 \%$ dos respondentes que concordam totalmente com a afirmativa de que a economia compartilhada pode alterar de forma significativa e positiva o seu padrão atual de vida. Identifica-se que a economia compartilhada proporciona facilidade no momento de efetuar compras, conexão e contato com pessoas conhecidas e desconhecidas, compartilhamento de informações através de sites de pesquisa e aplicativos de busca, possibilidade de fazer negócios e de economizar dinheiro. Percebeu-se que apenas $6 \%$ da amostra não sentiu diferença no seu comportamento, e que $1 \%$ da amostra discorda com a afirmação de que a economia compartilhada tenha mudado algum aspecto do seu modelo de vida.

A economia compartilhada pode facilitar o dia a dia, conectar as pessoas, fazer negócios, ampliar uma visão global através da Internet. As pessoas podem perceber as suas atividades de forma positiva, mas essa atitude positiva pode não ser traduzida em ações (Hamari et al., 2015). Ou, segundo Schor (2014), as pessoas podem participar do movimento motivadas por modismo ou pela novidade das plataformas.

A participação em redes sociais reforça a importância da comunidade, fortalece as preocupações ambientais e sociais, refletindo na mudança do estilo de vida (Palfrey \& Gasser, 2008). As mudanças no estilo de vida e nos padrões de consumo devem-se a três valores: (a) simplicidade: transações com relacionamentos mais próximos; (b) rastreabilidade e transparência: preocupação com a procedência do que se consome; (c) participação: os jovens não querem ser indiferentes em relação ao consumo atual (Bostman \& Rogers, 2011).

Assim, entende-se que, quanto a alteração do comportamento do consumidor frente à Internet, é necessário estar atento às demandas do mercado, e à mudança que a economia compartilhada proporciona tanto no que se refere ao acesso aos bens quanto aos fatores econômicos. A economia compartilhada permite que as pessoas fiquem menos dependentes de empregadores e mais capazes de diversificar as suas fontes de renda (Dubois et al., 2014).

\section{CONCLUSÕES}

O objetivo dessa pesquisa foi analisar a percepção de uma parcela dos cidadãos quanto aos efeitos econômicos e sociais proporcionados pela economia compartilhada no seu padrão atual de vida. O crescimento da economia compartilhada não representa uma mudança fundamental na natureza humana, e nem o fim da economia tradicional (Benkler, 2006). Neste sentido Rifkin (2014) sugere que o surgimento de uma economia híbrida, composta pelo mercado capitalista e pelos empreendimentos de compartilhamento podem desenvolver sinergias, adicionando valor uma à outra.

Para responder ao problema proposto, foi elaborado um questionário com o objetivo de levantar dados, no contexto da economia compartilhada, mais especificamente voltado a como funciona seu papel diante ao surgimento de novos negócios, e como é percebida a mudança do 
comportamento das pessoas frente ao movimento de compartilhamento. A pesquisa foi direcionada aos alunos da uma Instituição de Ensino Superior matriculados nos cursos de Ciências Exatas e Tecnológicas.

De acordo com dados obtidos nas respostas, foi possível descrever conclusões como: (a) mensurar o entendimento dos respondentes quanto ao assunto abordado; (b) identificar o conceito da economia compartilhada; (c) estabelecer uma relação da teoria com o perfil do público estudado.

Dessa forma, a pesquisa sugere evidências de que a economia compartilhada vem com intuito de auxiliar as pessoas na redução das suas despesas, promovendo novas formas de negócios e compartilhamento. E, ainda, que as pessoas estão compreendendo o quanto é desperdiçado o nosso bem mais precioso que é o tempo, em busca da satisfação momentânea de adquirir um bem. Também pode-se perceber que o futuro desta nova modalidade econômica ainda é incerto e dependerá do modelo de negócio e da natureza do serviço prestado pela organização (Schor, 2014).

A presente pesquisa contribuiu para o conhecimento conceitual e prático da academia sobre os temas de economia compartilhada. Também contribui para que se possa compreender a proposta que a economia compartilhada proporciona, que é centrada em oferecer, por exemplo, a possibilidade de economizar e ganhar dinheiro, alugando o que se possui, e que se pode mudar a relação entre o fato de ter o bem, e de ter acesso ao bem.

No entanto, admite-se que o processo de amostragem por conveniência realizado exclusivamente com estudantes universitários é uma limitação em termos do estudo. $\mathrm{O}$ desenvolvimento do presente estudo evidenciou que há muito que pesquisar no âmbito acadêmico e empresarial acerca do assunto proposto. Por tratarse de um fenômeno recente (economia compartilhada), existe pouca literatura neste contexto. Além disso, no mercado brasileiro não existe regulamentação específica para aplicativos, plataformas e novos negócios nesses segmentos. Dessa forma, recomenda-se a realização de outras pesquisas sobre o tema, voltadas ao âmbito das plataformas de negócios empresariais para empresas que já estão no mercado.

\section{REFERÊNCIAS}

Bardhi, F., \& Eckhardt, G. M. (2012). Access-based consumption: The case of car sharing. Journal of Consumer Research, 39(4), 881-898.

Belk, R. (2014). You are what you can access: Sharing and collaborative consumption online. Journal of Business Research, 67(8), 1595-1600.

Benkler, Y. (2006). The wealth of networks: How social production transforms markets and freedom. Yale University Press, 2006.

Bostman, R., \& Rogers, R. (2011). O que é meu é seu: como o consumo colaborativo vai mudar o nosso mundo. Bookman Editora.

Cheng, M. (2016). Sharing economy: A review and agenda for future research. International Journal of Hospitality Management, 57, 60-70.

Cusumano, M. A. (2015). How traditional firms must compete in the sharing economy. Communications of the $A C M, 58(1)$, 32-34.

Denning, S. (2014). An economy of access is opening for business: five strategies for success. Strategy \& Leadership, 42(4), 14-21.

Dubois, E., Schor, J., \& Carfagna, L. (2014). Connected consumption: A sharing economy takes hold. Rotman Management, 50-55.

El Fassi, A., Awasthi, A., \& Viviani, M. (2012). Evaluation of carsharing network's growth strategies through discrete event simulation. Expert Systems with Applications, 39(8), 6692-6705.

Fan, W., \& Yan, Z. (2010). Factors Affecting Response Rates of the Web Survey: A Systematic Review. Computers in Human Behavior, 26(2), 132-139.

Freitas, C., Petrini, M., \& Silveira, L. (2016). Desvendando o consumo colaborativo: uma proposta de tipologia. In: CLAV - Latin American Retail Conference. São Paulo.

Gansky, L. (2010). The mesh: Why the future of business is sharing. Penguin.

Hamari, J., Sjöklint, M., \& Ukkonen, A. (2015). The sharing economy: Why people participate in collaborative consumption. Journal of the Association for Information Science and Technology, 67(9), 2047-2059.

Hsieh, M. L., \& Dawson, P. H. (2010). A university's information literacy assessment program using Google Forms. In: Brick and click libraries: Proceedings of an academic library symposium (10th, Maryville, Missouri, November 5, 2010).

Lamberton, C. P., \& Rose, R. L. (2012). When is ours better than mine? A framework for understanding and altering participation in commercial sharing systems. Journal of Marketing, 76(4), 109-125.

Leismann, K., Schmitt, M., Rohn, H., \& Baedeker, C. (2013). Collaborative consumption: towards a 
resource-saving consumption culture. Resources, 2(3), 184-203.

Martin, C. J. (2016). The sharing economy: A pathway to sustainability or a nightmarish form of neoliberal capitalism? Ecological Economics, $121,149-159$.

Menezes, L. S., Sellitto, M. A., Librelato, T. P., Borchardt, M., \& Pereira, G. M. (2016). Identification and Quantification of Influent Factors in Perceived Quality of the E-Service Provided by a University. Business Process Management Journal, 22(3), 438-457.

Möhlmann, M. (2015). Collaborative consumption: determinants of satisfaction and the likelihood of using a sharing economy option again. Journal of Consumer Behaviour, 14(3), 193-207.

Nunes, F. L. (2016). Aplicação do Peer Instruction no ensino tecnológico superior com o auxílio do Google Forms: um estudo de caso. Anais do XXII SIMPEP - Simpósio de Engenharia de Produção - Bauru -São Paulo.

Palfrey, J., \& Gasser, U. (2013). Born digital: Understanding the first generation of digital natives. Basic Books.

Piscicelli, L., Cooper, T., \& Fisher, T. (2015). The role of values in collaborative consumption: insights from a product-service system for lending and borrowing in the UK. Journal of Cleaner Production, 97, 21-29.

Porter, M. E. (2008). On competition. Harvard Business Press.

Prodanov, C. C, \& Freitas, E. C. (2009). Metodologia do trabalho científico: Métodos e técnicas da pesquisa e do trabalho acadêmico. 2.ed. Novo Hamburgo: Feevale.
Rifkin, J. (2014). The zero marginal cost society. 356.

Ritzer, G., Dean, P., \& Jurgenson, N. (2012). The coming of age of the prosumer. American Behavioral Scientist, 56(4), 379-398.

Ritzer, G., \& Jurgenson, N. (2010). Production, Consumption, Prosumption The nature of capitalism in the age of the digital 'prosumer'. Journal of Consumer Culture, 10(1), 13-36.

Schor, J. (2014). Debating the sharing economy, Great Transition Initiative.

Shaheen, S. A., Mallery, M. A., \& Kingsley, K. J. (2012). Personal vehicle sharing services in North America. Research in Transportation Business \& Management, 3, 71-81.

Sheehan, K. B. (2001). E-mail survey response rates: A review. Journal of Computer-Mediated Communication, 6(2), 0-0.

Silveira, L. M. da, Petrini, M., \& Santos, A. C. M. Z. dos. (2016). Economia compartilhada e consumo colaborativo: o que estamos pesquisando? Revista de Gestão, 23(4), 298-305.

Spaeth, A. D., \& Black, R. S. (2012). Google Docs as a form of collaborative learning. Journal of Chemical Education, 89(8), 1078-1079.

Tukker, A., \& Tischner, U. (2006). Product-services as a research field: past, present and future. Reflections from a decade of research. Journal of Cleaner Production, 14(17), 1552-1556.

Villanova, A. L. (2015). Modelos de negócio na economia compartilhada: uma investigação multi-caso. Dissertação de Mestrado em Administração de Empresas na Fundação Getúlio Vargas (FGV).

\title{
The shared economy and the perception of its effects by the students of a higher education institution
}

\begin{abstract}
In times of financial instability, doubts arise regarding the financial market and the economic situation of a country. These moments are conducive to the emergence of new economic movements, such as the shared economy. It is understood as relevant to develop papers that analyze the perception of society about the effects provided by the shared economy. Seeking to contribute in this sense, the objective of this work is to analyze the perception of a portion of the citizens about the economic and social effects provided by the shared economy in their current standard of living. To fulfill the proposed objective, a survey was carried out with students from a Higher Education Institution in Rio Grande do Sul - Brazil. Among the main results, it was observed that a range of $67.9 \%$ to $83.3 \%$ of the respondents fully agrees with the affirmation that the shared economy generates positive social and economic impacts, which allows a change in their current standard of living. It is identified that the shared economy arises from a dichotomy between the opportunity to generate new business and a response to economic crises. In addition, it provides ease in making purchases, connection and contact between people known and unknown, sharing information through search sites and search applications, and the possibility of doing business and save money.
\end{abstract}

Keywords: Shared Economy, Business Model, Collaborative Consumption, Generation of the Millennium. 